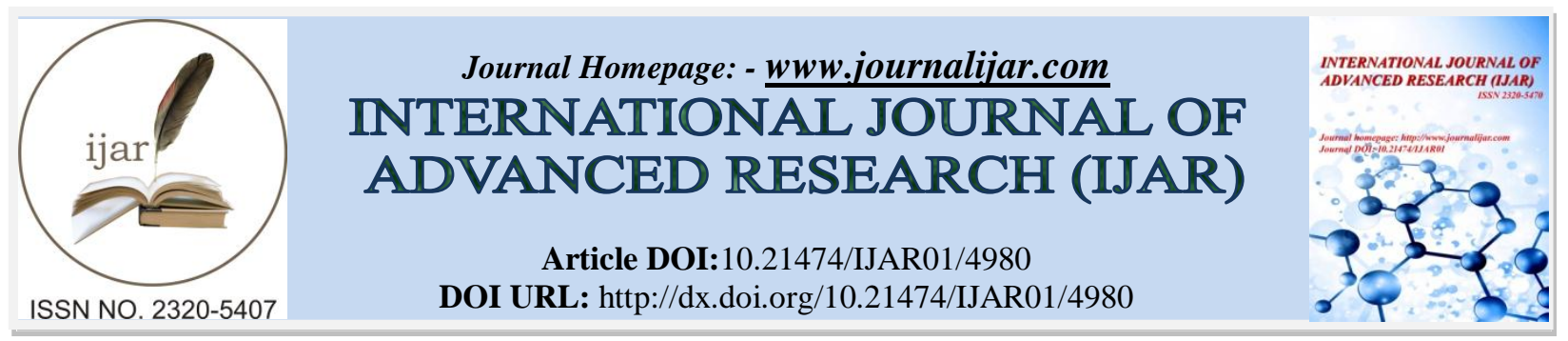

RESEARCH ARTICLE

\title{
THE POSSIBILITY OF ADDING A MANUAL FORMATION TO CERAMIC PRODUCTSAND RE-BURN
} THEM.

Dr.Faten Abdel-Fattah Metwally Ali.

Faculty of Applied Arts, ceramic department, Helwan University, Egypt.

\section{Manuscript Info}

.........................

Manuscript History

Received: 27 May 2017

Final Accepted: 29 June 2017

Published: July 2017

\section{Abstract}

Research depended on the practical application of preparing clay that has the ability of self-adhesion on ceramic. Without separation after the drought (burning), as well as its lack of deflation property, have plasticity appropriate, ability coloring by porcelain color (glaze and lining and stains and others), and finally has the potential to burn once for each of clay and glaze. Experiments have been conducted in this regard at the local clay (Aswan clay, Pall Clay) to obtain the required specifications, those specifications were available through the improvement of the local clay specifications and get the clay suitable. The application took place on different products and conduct experiments in this clay, showed satisfactory results. This may be useful in several areas, including that solves some technical problems with the ceramic producers, whether artists or in the field of industry and quantitative production in the porcelain, they can keep ceramic products which lost parts of them, due to these products may be have artistic or literary value great.

Copy Right, IJAR, 2017,. All rights reserved.

\section{Introduction:-}

There is a problem since the origin of the porcelain industry that faced the porcelain producers, whether artists or manufacturers, it is that ceramic cannot be modified after drought or fire, which is an obstacle facing the potter especially if was lose part of the piece of ceramic during the fire or trading or other. and may this has happened to piece with a highly artistic and technical value, the objective of this research is the possibility of addressing this issue by adding a manual formation by using processor clay, to biscuits shape, or even after the second heartburn (product covered with glaze)., Using the properties of clay processor qualifies it to do this purpose, in terms of plasticity and sticking with the ceramic and portability colouring with porcelain colours on its dry surface and not shrinking, and finally burn once.

\section{Aim of the research:-}

The research aims at the possibility of modifying the ceramic shape that has already burnt or covered with glaze by adding a formation by cly prepared for this purpose, and the possibility of covering the added part or the whole shape by glaze, or other suitable ceramic colours, and then burning the ceramic shape again 


\title{
Research importance:-
}

The importance of the research is solving the technical problem facing the potters since the start of this industry. the solution is the possibility of adding the formation of clay on the biscuit ceramic or glazed ceramic, then, add glaze or other ceramic colours on the additive clay, or on the all product, and then burn the product again.

\section{Research methodology:-}

It is empirical research and descriptive approach by conducting laboratory experiments, observation and discussion of the results and description.

\section{Research hypotheses:-}

Finding a technique to possibly add the formation of clay on the ceramic products in stages after the first burning (biscuits) or after the second arson (glaze).and possibility of applied glaze on formation clay after the dry step, then burn a the whole piece.

\section{Research problem:-}

The problem of research in the potters' inability to add an amendment to the form of the ceramic after the first or second heartburn, forcing sometimes to a loss in a ceramic piece as a result of the inability to complete the lost portions of them .

\section{Research steps:-}

The idea of research is to get the clay to have a special specification allows its use as a supplement for some ceramic forms scorched having these qualities:-

1. The possibility of self-sticking with the body ceramic (at the stage of biscuits - glazed ceramic.) which gives a smoother shape and the integration of logical and does not need external adhesive

2. A plasticity suitable for manual formation.

3. Retained of form added after the stages of drought and burn.

4. Portability colouring by various ores porcelain.

5. Has the ability to burn once with glaze.

6. Acquires hardening appropriately after the fire and the layer color homogeneous.

7. It doesn't shrink after drought and fire.

\begin{abstract}
Applications:-
Some practical experiments carried out on the earthen clay in order to improve its properties, to get a clay thathave the required specifications, along with the rest of the required specifications, by adding materials and ores that resist the downturn, does not affect the plasticity necessary for the formation as well as the porosity and other natural specifications of the clay.These properties have been available in one of the experiments, which resulted in the clay enhancer.It has applied some practical experiences on this improved clay to test the following:

1. Possibility of using the mud to complete portions of the ceramic product (biscuits).

2. Then adding the glaze on the product supplement and burn again to get a glazed ceramic product.

3. The possibility to use this clay to complete portions of the ceramic product (glazed).

4. Then add the glaze on the appropriate supplementing and burn it again to get a glazed ceramic product.
\end{abstract}

After conducting many experiments on the local earth clay, a range of wares improved clay was obtained, which has the characteristics desired from where plasticity and portability colouring with glaze on the body in the dry phase, burning at once. (Pictures1 \&2) 


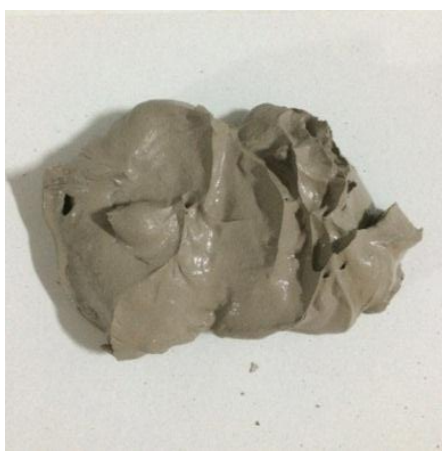

Picture 1

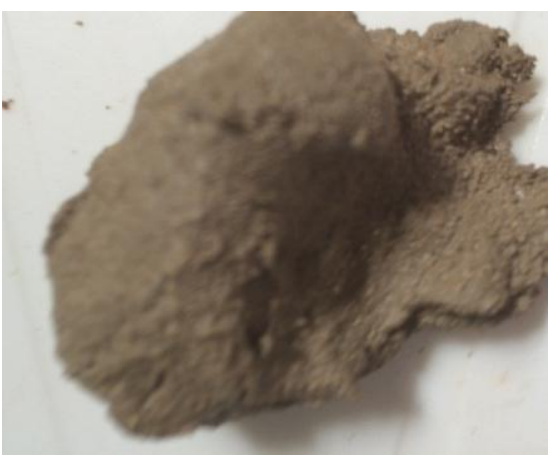

Picture 2

A picture $1 \& 2$ of the improved clay that provided the required specifications.

\section{Application:-}

The clay has been used in the formation of the handle (missed) of the casserole,form by earth clay, and has passed two stages of the fire (Picture 3). The success of the experiment has been observed in forming and drought stage, where part additive has been joined, with ceramic saucer was not separated during the formation or drought (Picture 4 ) Transparent glaze has been used to cover the handle.

Glaze has been accepted on new part after drought without problems (Picture 5).

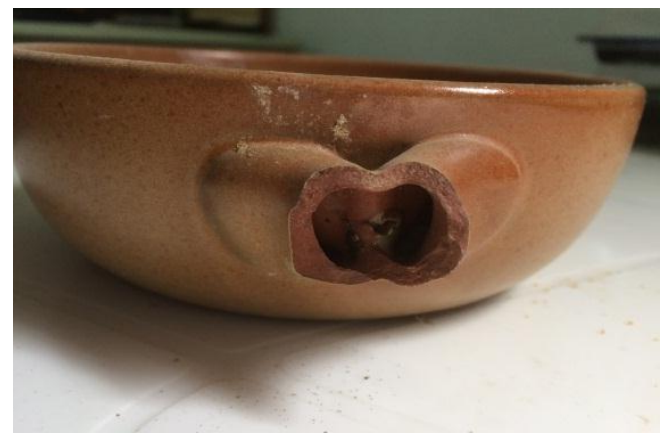

Picture 3

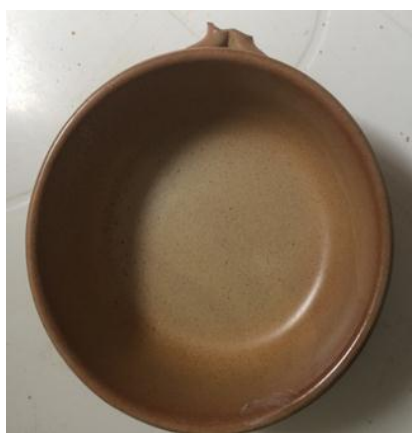

Picture 4

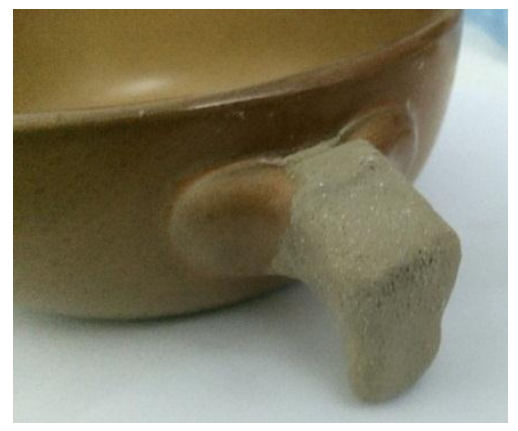

Picture 5

part additive retained the shape and dimensions after the drought Transparent glaze havebeen used to cover the handle.Glaze has been accepted on new part after drought without problems (Pictures 6).

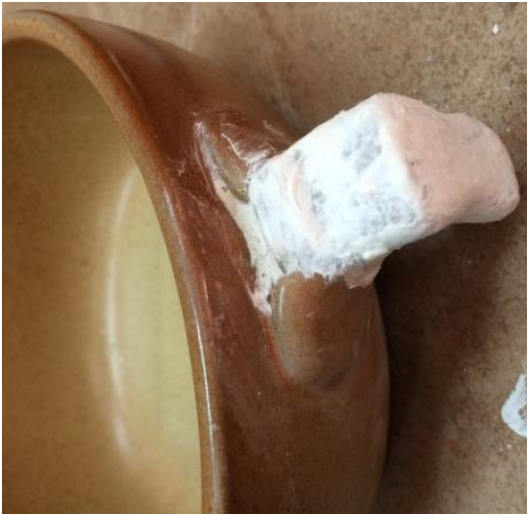

Picture 6

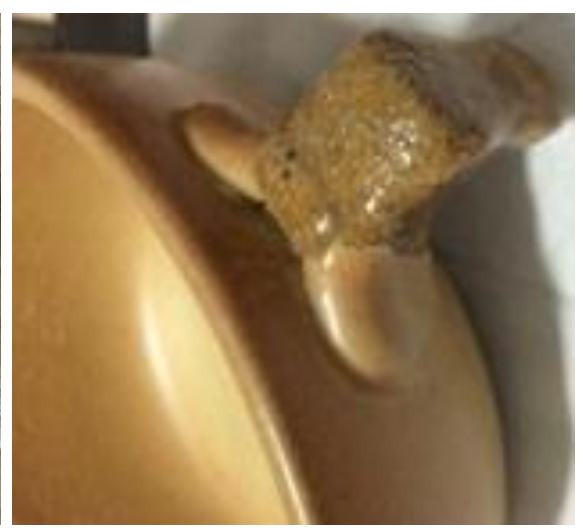

Picture 7 


\section{Notes:-}

The added part is perfectly aligned with the dish during formation, after drying, after coating and burning.(Pictures 7).The added part was tested after burned and was observed to be inseparable from normal use, or by trying to forcefully compress it.

There is a clear difference between the colour of the dish and the colour of the added part due to the use of a different composition glaze than the original glazes of the dish. This can be avoided if the same type of glaze is used, taking into account the application of the clay lining used to form the dish on the added part before applying the glaze.

\section{Application 2:-}

The possibility of using this clay to complete the parts of the piece of ceramic biscuits and add a glass coating and burn the second burn.The shape is an outlet jug for artistic purpose and biscuit (Picture $8,9,10$ )

The application of the glaze is completed in preparation for the second burned.

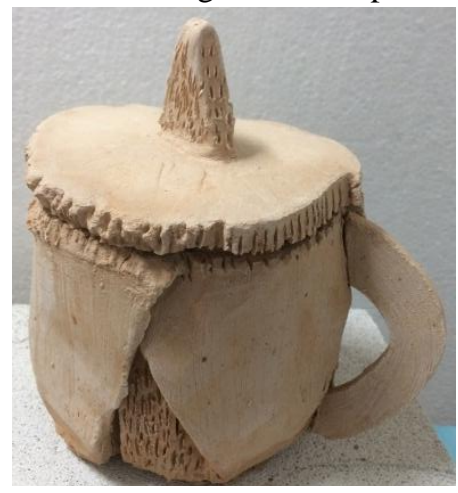

Picture 8

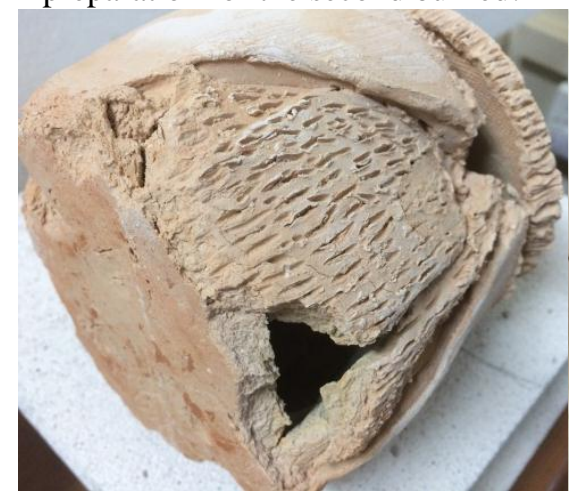

Picture 9

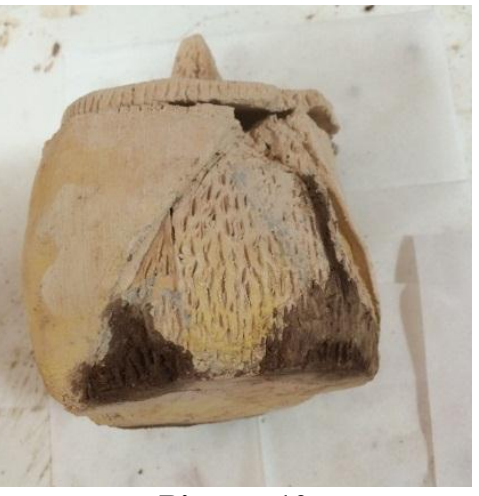

Picture 10

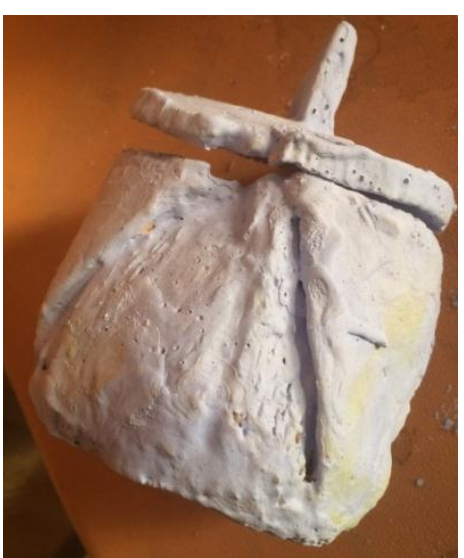

Picture 11

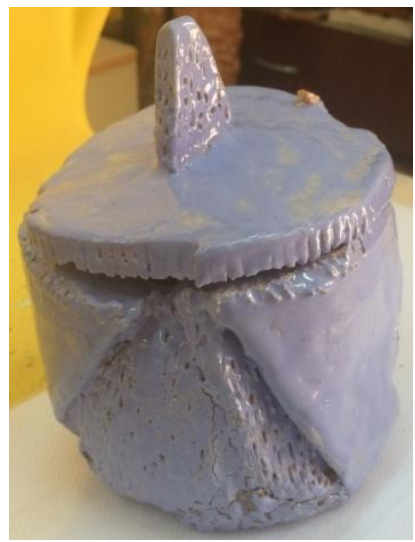

Picture 12

After completion and the glaze were applied and the shape was completely covered with a coloured glass, The shape was burned. (Pictures $11 \& 12$ )

\section{Notes:-}

1. The colour of clay used for completion is different from the pottery colour of the shape.

2. The use of opaque glaze hides the colour difference between the used clay and pottery colour.

3. The added part is consistent with the shape before and after the burn.

4. The added part has become a colour similar to the colour shape due to opaque glaze. 


\section{Third Application:-}

This work was applied to the work of ceramics made of clay Aswan, and work is formed in the form of sunflower, but some of the leaves of the flower lost during the burning of biscuits, and some of them lost part of these leaves. (Picture 13).

1. The clay prepared for this purpose was used to form the pieces and the leaves that were lose.(Picture 14).

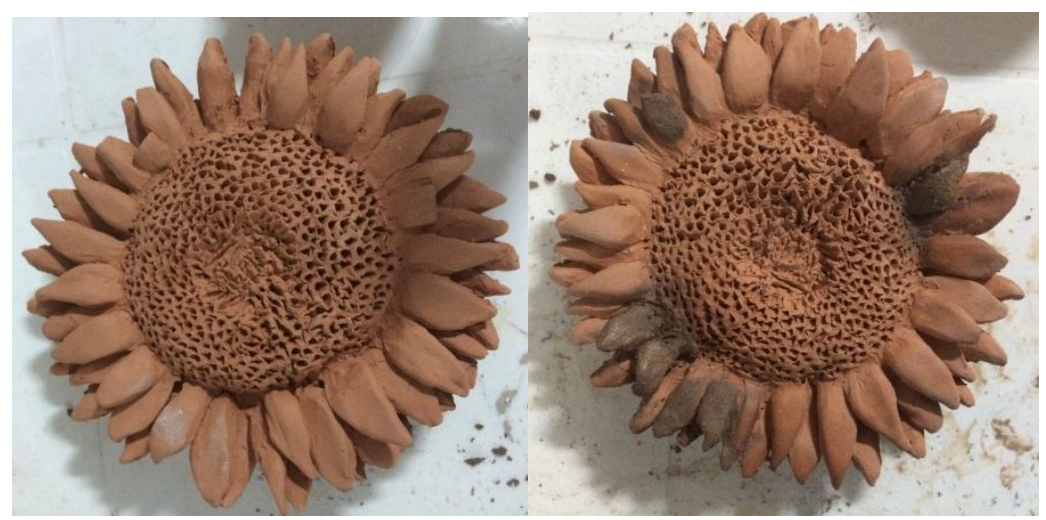

Picture 13

Picture 14

2. Apply glass coating directly to shape_on both biscuit parts and clay parts _ (Picture 15).

3. The shape was burnt at $1050^{\circ} \mathrm{C}$. (Photo

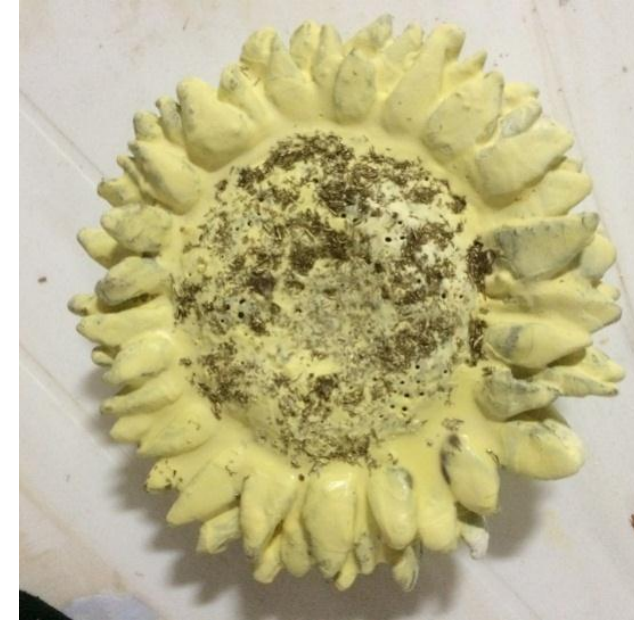

Picture 15

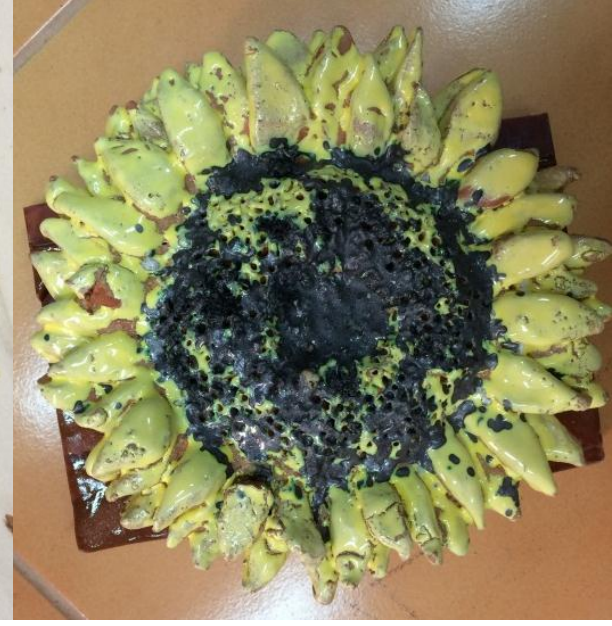

Picture 16

4. The colour of clay used for completion is different from the pottery colour of the shape.

5. The use of dark glaze hides the colour difference between clay used and pottery .(Picture 16).

\section{Recommendations:-}

General Recommendations:-

1. The completion process by the person who made the shape himself so as not to lose shape of its original features.

2. The possibility of completion by experts with the consent of the employer or take action that gives the right to this.

\section{Recommendations for the completion of non-glazed pottery:-}

Observe the use of opaque glaze to avoid the appearance of colour difference between the added clay and the colour of pottery. 
Apply a lining layer of the shape clay to the complementary part to ensure that the same colour of the glaze is obtained after it interacts with the lining particles..

\section{Recommendations for the completion of glazed pottery:}

1. Use the same colour of glass coating of the complementary form if possible.

2. Laying a layer of lining of the shape on the complementary part to ensure the same degree of colour of the gel after the interaction with the lining particles .

\section{Results:-}

1. Get the clay fitting to have the ability to stick with the porcelain shapes. - whether clay, biscuits, or glazed.

2. The ability of the clay to form and complete the missing parts of the ceramic forms. - Whether clay or biscuits, or glazed.

3. The presence of the non-deflation as one of the characteristics of this clay, making it successful in completing the burned forms.

4. The clay shall accept the glass coating on its surface before burning and its result did similar to that applied to the surface of the ground mud.

\section{References:-}

1. Frank Hamer, The Potter's Dictionary of Materials and Techniques, University Pennsylvania Press; 4th edition (1 Jun. 1997).

2. James C.Watkin\& Paul Andrew Wandless, alternative kilns \& firing techniqu,: Raku * Saggar * Pit* Barrel (A Lark Ceramics Book) Paperback - September 28, 2006

3. Maureen mills, surface design for ceramics, Lark Crafts (April 5, 2011)

4. John Britt ,the complete guide to MID-RANGE GLAZES: Glazing and Firing at Cones 4-7 (Lark Ceramics Books) Hardcover - November 4, 2014.

5. Joaquim Chavarria,The Big Book of Ceramics: A Guide to the History, Materials, Equipment and Techniques of Hand-Building, Throwing, Molding, Kiln-Firing and Glazing Pottery and Other Ceramic Objects, WatsonGuptill; First U.S. edition (September 1, 1994)

6. Louisa Taylor,The Ceramics Bible: The Complete Guide to Materials and Techniques Chronicle Books; 1st edition (September 7, 2011). 